\title{
Search effort and imperfect detection: Influence on timed-search mussel (Bivalvia: Unionidae) surveys in Canadian rivers
}

\author{
S.M. Reid ${ }^{\star}$
}

Aquatic Research and Monitoring Section, Ontario Ministry of Natural Resources and Forestry, Trent University - DNA Building, 1600 West Bank Drive, Peterborough, Ontario, K9L 0G2, Canada

Received November 18, 2015 - Revised January 26, 2016 - Accepted February 4, 2016

\begin{abstract}
Inventories and population monitoring are essential activities supporting the conservation of freshwater mussel diversity in Canadian rivers. Despite widespread use of timed-search methods to survey river mussels, the relationship between species detection and search effort has received limited study. In this study, repeat-sampling data from 54 Ontario river sites were used to estimate: (1) species detection probabilities; (2) the number of sampling events required to confidently detect species; and, (3) the power of timed-search surveys to detect future distribution declines. Mussels were collected using visual and tactile methods, and collection data were recorded separately for each $1.5 \mathrm{~h}$ of search time (up to $4.5 \mathrm{~h}$ ). Thirteen species were collected; including two endangered species (Rainbow Villosa iris and Eastern Pondmussel Ligumia nasuta). In all cases, species detection was imperfect. However, detection probabilities $(p)$ for most species were high $(>0.69)$. Two repeat $4.5 \mathrm{~h}$ surveys are required to confidently assess whether most $(83 \%)$ species are present at a site. Search effort had a positive effect on estimates of species richness, detection probability and site occupancy, and the power to detect future distribution declines. At all levels of sampling effort, detection probability and site occupancy estimates were positively correlated to mussel abundance.
\end{abstract}

Key-words: Unionids / endangered species / monitoring / sampling design

Résumé - Effort de prospection et détection imparfaite : Influence de la prospection chronométrée d'échantillonnage de moules (Bivalvia : Unionidae) dans les rivières canadiennes. Les inventaires et la surveillance de populations sont des activités essentielles pour soutenir la conservation de la diversité des moules d'eau douce dans les rivières canadiennes. Malgré l'utilisation généralisée de méthodes chronométrées pour étudier les moules de rivière, la relation entre la détection des espèces et l'effort de recherche a été peu étudiée. Dans cette étude, des données d'échantillonnage répété de 54 sites de rivière de l'Ontario ont été utilisées pour estimer : (1) les probabilités de détection de l'espèce; (2) le nombre d'événements d'échantillonnage requis pour détecter de façon fiable toute les espèces; et, (3) la puissance des échantillonnages chronométrés pour détecter de futures baisses de distribution. Les moules ont été recueillies à l'aide des méthodes visuelles et tactiles, et des données de collecte ont été enregistrées séparément pour chaque $1,5 \mathrm{~h}$ de temps de recherche (jusqu'à $4,5 \mathrm{~h}$ ). On a récolté treize espèces; y compris deux espèces en voie de disparition (Rainbow Villosa iris and Eastern Pondmussel Ligumia nasuta). Dans tous les cas, la détection des espèces était imparfaite. Cependant, les probabilités de détection $(p)$ pour la plupart des espèces étaient élevées $(>0,69)$. Deux répétitions de $4,5 \mathrm{~h}$ de prospection sont nécessaires pour évaluer en toute confiance que la plupart ( $83 \%)$ des espèces sont présentes sur un site. L'effort de recherche a eu un effet positif sur les estimations de la richesse en espèces, la probabilité de détection et de l'occupation du site, et le pouvoir de détecter les futures baisses de distribution. À tous les niveaux de l'effort d'échantillonnage, les estimations de probabilité de détection et d'occupation du site étaient positivement corrélées à l'abondance des moules.

Mots-clés : Unionidés / espèces menacées / surveillance / conception d’échantillonnage

\section{Introduction}

North American water bodies contain the most diverse collection of freshwater mussels (family: Unionidae) in the world. However, freshwater mussels are also considered the most

\footnotetext{
^ Corresponding author: reid.scott@ontario.ca
}

imperiled faunal group in North America (Williams et al., 1992). Historical mussel fauna declines were related to the degradation of riverine habitats (e.g. the construction of dams and impoundments, loss of riparian zones, and water pollution) and commercial harvest (Metcalfe-Smith et al., 1998; Haag, 2012). More recent and rapid declines have occurred since 
the introduction (and spread) of non-native dreissenid mussels to the Laurentian Great Lakes (Schloesser and Nalepa, 1994; Lucy et al., 2013). In Canada, the greatest diversity of freshwater mussels is found in the province of Ontario. Fifteen of the 41 freshwater mussel species found in Ontario are listed as Endangered, Threatened or Special Concern under the federal Species at Risk Act and the provincial Endangered Species Act (COSEWIC, 2013; MNRF, 2014). Actions undertaken to protect and recover Ontario's mussels include surveys and the establishment of population index monitoring stations. Data collected through inventory and monitoring activities are essential for delineating areas of protected habitat, assessing population status and trends, and evaluating the effectiveness of recovery actions (Cudmore et al., 2006; DFO, 2011).

In contrast to Laurentian Great Lakes habitats, most rivers are not heavily infested by dreissenids and historical mussel diversity is largely intact (McNichols-O'Rourke et al., 2012); providing important refugia for native mussels from dreissenid impacts (Clarke, 1992). Timed-search methods are commonly used for river mussel surveys (e.g. McNichols-O'Rourke et al., 2012; Epp et al., 2013; Randklev et al., 2013); as some authors consider timed-search surveys to be more effective and efficient at rare species detection than quadrat sampling (Metcalfe-Smith et al., 2000). A greater variety of habitats are targeted during visual and tactile sampling, and therefore, a greater number of species are expected to be collected. In addition to developing species lists for river reaches or watersheds, timed search data can be used to inform the design of more intensive (and costly) sampling efforts to estimate mussel population densities (Strayer and Smith, 2003). If the monitoring objective is to track changes in species distribution, the effort required to reliably detect a species may also be substantially less than tracking changes in abundance with quantitative sampling (i.e. quadrats) approaches (Gibbs et al., 1998).

Freshwater mussel detection can be challenging as they often occur at low densities, are spatially clustered and imperfectly detected (Smith et al., 2010). Past studies have found that detection is affected by a variety of factors, including: shell size and sculpture (Hornbach and Deneka, 1996); whether a mussel tends to be epibenthic or endobenthic (Amyot and Downing, 1991); river flow conditions and composition of bed material (Villella et al., 2004; Wisniewski et al., 2013a); and, experience of field staff (Wisniewski et al., 2013a). Despite its widespread use, the relationship between species detection and search effort during qualitative river mussel sampling has received limited study (Strayer and Smith, 2003). To ensure that mussel surveys provide meaningful results, it is important to assess the effect of sampling design choices, such as search effort.

In this study, I used a repeat-sampling approach (MacKenzie et al., 2002) to model the relationship between search effort and detection of freshwater mussel species. Species detection histories associated with discrete replicate surveys were used to jointly model occupancy (i.e. the proportion of sampled sites occupied) and detection probabilities. The approach has been broadly used for other aquatic and semi-aquatic taxa (Jeffress et al., 2011; Schloesser et al., 2012; Pearl et al., 2013; Dextrase et al., 2014; Smith et al., 2014), but rarely for freshwater mussels (Wisniewski et al., 2013a).
Monitoring programs can use such repeat-sampling data to monitor changes in species distribution, while adjusting for the bias associated with imperfect detection. In this study, repeatsampling data were used to estimate: (1) species-specific detection probabilities; (2) the number of sampling events required to confidently detect species; and, (3) the power of timed-search surveys to detect future distribution (or occupancy) declines. Mussel collection data were also used to characterize: (1) the influence of search effort on species richness estimates and detection of rare species; and (2) the level of agreement among collections by different field crew members.

\section{Materials and methods}

\subsection{Mussel sampling}

Fifty-four wadeable sites along the Trent $(n=35)$, Moira $(n=12)$ and Salmon $(n=7)$ rivers were sampled. The three southern Ontario rivers flow into the Bay of Quinte, eastern Lake Ontario ( $\left.44^{\circ} 08^{\prime} 54^{\prime \prime} \mathrm{N} ; 77^{\circ} 22^{\prime} 46^{\prime \prime} \mathrm{W}\right)$. Sites were selected based on historical records of the endangered Rainbow Mussel (Villosa iris),suitability of habitats for sampling (i.e. searches could be safely undertaken by foot) and permission to access private lands. Trent River sites were located along both the river mainstem and four tributaries (Cold, Percy, Rawdon and Salt creeks). As part of the Trent-Severn Waterway, the Trent River has been highly fragmented by navigational and run-ofthe-river hydro-electric dams. The Moira and Salmon rivers are fragmented by old mill, low flow augmentation, and flood control dams. Surficial geology of the study area is a complex mix of Precambrian and Paleozoic (limestone) bedrock, glacial deposits and limestone till (Chapman and Putnam, 1984); resulting in a wide range of flow and bed material characteristics across sampling sites (Reid et al., 2005). Reach lengths surveyed ranged from 31 to $362 \mathrm{~m}($ mean $=134 \mathrm{~m})$; channel widths ranged from 5 to $175 \mathrm{~m}($ mean $=27 \mathrm{~m})$. Mean water depths ranged from 0.14 to $0.71 \mathrm{~m}$.

Live mussels and fresh shells were collected using a timesearch method developed for the detection of rare species (Metcalfe-Smith et al., 2000). A three person crew searched for mussels at each site with the aid of mussel viewers and polarized sunglasses. No fixed search pattern was used during visual and tactile sampling, and not all habitats were sampled in a site. Instead, crew members spread out and focused on suitable mussel habitats (e.g. riffles and margins of islands). Habitats too deep to be safely or effectively sampled were bypassed. The area searched by each person did not overlap. Mussel searches did not include the excavation of the riverbed.

Sampling effort was broken down into three 1.5 hour (h) intervals for a total of $4.5 \mathrm{~h}$ of sampling. Live individuals and shells were identified to species (Metcalfe-Smith et al., 2005). Live individuals were enumerated by each $1.5 \mathrm{~h}$ sampling interval, and crew member. Species detections associated with shells were recorded for each sampling event. Each site was sampled on three separate dates. First and last sampling visits were separated, on average, by 45 days (range: 18-97). Across site sampling visits, areas searched were rotated among crew members so that habitats were not resampled by the same person. Sampling was completed between 4 June 
and 25 September 2013 along the Trent River, and 27 June and 26 September 2014 along the Moira and Salmon rivers. Within each year, the membership of field crews was the same. Mussel fieldwork experience ranged from 0 to seven years in 2013, and from one to two years in 2014.

\subsection{Data analysis}

For each year, the similarity of mussel collections among field crew members was assessed by comparing the number of individuals collected and the number of species detected and, calculating an extension of Cohen's Kappa statistic for multiple observers (Fleiss et al., 2003, Agresti, 2013). The Kappa statistic is an index of agreement between different classification methods; with +1 indicating perfect agreement and 0 indicating a level of agreement that would be expected by chance alone. For each species, Fleiss's Kappa was calculated using site detection histories ( 0 for absent, 1 for present) associated with the three sampling events completed by each field crew member.

To evaluate the effect of search effort (1.5, 3.0 and $4.5 \mathrm{~h}$ ) on the number of species detected (richness) during surveys, sample-based rarefaction curves were computed using Mao's $\tau$ (Colwell et al., 2004). Species richness was estimated based on the frequency of species that occurred only once (singletons) or twice (doubletons) in a sample. Curves were computed using data from the first sampling visit and the software PAST version 1.94 (Hammer et al., 2001). To determine the effect of increasing sampling effort on the detection of locally rare species, the species were classified as rare (1-5 individuals per $4.5 \mathrm{~h}$ sampling event), uncommon (6-10 individuals) or common ( $>10$ individuals) for each site (Metcalfe-Smith et al., 2000). For each abundance category, the level of effort required to first detect species at a sampling site was identified and summarized.

For 12 species, the probability of at least one individual being detected $(p)$ from a site and the probability of a site being occupied by a species $(\psi)$ were estimated using PRESENCE 9.7 (2015) software (http://www.mbr-pwrc.usgs. gov/software/presence.html). Using repeat sampling data, site occupancy and detection probability are jointly estimated using a multinomial likelihood occupancy model (MacKenzie et al., 2006). The method parallels a closed-population, Capture-Mark-Recapture model, with an additional parameter representing probability of species presence (MacKenzie et al., 2002). Occupancy models use detection probabilities to adjust estimates of naïve occupancy (the proportion of sites observed to be occupied by a species); thereby reducing bias associated with imperfect species detection. Probabilities were estimated using detection histories from three successive sampling events, and the constant probability, single-season model (MacKenzie et al., 2002). Single-season models assume that sites are closed to immigration or emigration at the species level. Probabilities were estimated using detection histories for: (1) live individuals associated with $1.5 \mathrm{~h}, 3.0 \mathrm{~h}$ and $4.5 \mathrm{~h}$ of cumulative search effort, and (2) live individuals plus fresh shells collected during $4.5 \mathrm{~h}$ of cumulative search effort. Detection probabilities were not estimated for Eastern Pondmussel (Ligumia nasuta), because it was collected from only one site. The Spearman rank correlation was used to test for positive relationships between number of individuals collected at a site and estimates of $p$ and $\psi$.

Detection probabilities were used to estimate the minimum number of repeat surveys $\left(N_{\min }\right)$ required to confidently detect a species at a sampling site. For the analysis, a repeat survey refers to multiple sampling events that are undertaken on different dates. $N_{\min }$ was calculated with the formula:

$$
\log (1-C L) / \log (1-p) \quad \text { (Pellet and Schmidt, 2005). }
$$

The confidence level (CL) was 0.95 (i.e. $95 \%$ confident that a species is absent from a site).

A prospective power analysis was undertaken to evaluate whether timed search sampling could reliably detect future declines in species distributions. Using $p$ and $\psi$, power estimates were calculated for each species using an Excel-based sample size/power calculator (OccPower.xlsx). The power to detect differences in species occupancy between two independent, single-season surveys is calculated using a closed-form estimator (equation (3) in Guillera-Arroita and Lahoz-Monfort, 2012). Power (based on the critical region of a two-tailed test) is a function of the initial occupancy estimate $(\psi)$, proportional change in occupancy between surveys $(R)$, species detection probability $(p)$, number of replicate surveys $(K)$, and number of sites surveyed $(S)$. The likelihood of detecting a change in occupancy between surveys improves as parameter values increase. Rates of declines $(R=30,50$ and $70 \%)$ were based on the quantitative criteria applied during Canadian (Committee on the Status of Endangered Wildlife in Canada, www.cosewic.gc.ca) and international (IUCN Red List of Threatened Species, www.iucnredlist.org) assessments of species status. A Type I error rate of 0.05 was adopted. Estimates of power $\geqslant 80$ are considered high (Cohen, 1988).

\section{Results}

\subsection{Summary of collections}

Thirteen species were collected from the Trent $(n=12$ species), Moira $(n=10)$ and Salmon rivers $(n=11)$. Species diversity ranged from 1 to 10 species per site (median $=7$ species). Mussel assemblages were less diverse than found in southwestern Ontario rivers (Lake Erie and Lake St. Clair watersheds) (Metcalfe-Smith et al., 1998). Seventytwo percent of species detections were from the collection of live individuals and $28 \%$ from the collection of fresh shells. Mean catch per unit effort (CPUE) of live mussels was similar among rivers: 48.2 mussels. $\mathrm{h}^{-1}$ along the Trent River, 44.2 mussels. $\mathrm{h}^{-1}$ along the Salmon River and 42.0 mussels. $\mathrm{h}^{-1}$ along the Moira River. The most abundant species was Eastern Elliptio (Elliptio complanata), comprising $72 \%$ of all live individuals collected. Individually, other species represented less than $9 \%$ of collections. The most widespread species were Elktoe (Alasmidonta marginata), Eastern Elliptio, Fatmucket (Lampsilis siliquoidea), Creek Heelsplitter (Lasmigona compressa), and Flutedshell (Lasmigona costata) (Table 1). Two mussel species-at-risk were detected (Rainbow Mussel from 24 sites, and Eastern Pondmussel from one Trent River site).

In 2013, there was little variation among crew members in the number of individuals collected and species detected 
S.M. Reid: Knowl. Manag. Aquat. Ecosyst. (2016) 417, 17

Table 1. Summary of freshwater mussel collection data based on repeated timed-searches $(4.5 \mathrm{~h})$ at 54 southern Ontario river sites.

\begin{tabular}{|l|c|c|c|c|}
\hline Species & Total Number & Rank Abundance & Naive Occupancy $^{2}$ & Mean (range) Shell Length \\
\hline Alasmidonta marginata & 17 & 11.7 & 5 & $57(34-74)$ \\
Alasmidonta undulata & 37 & 10.7 & 4 & $43(24-54)$ \\
Anodontoides ferussacianus & 540 & 3.3 & 18 & $49(18-95)$ \\
Elliptio complanata & 8244 & 1 & 41 & $68(11-131)$ \\
Lampsilis cardium & 91 & 9 & 14 & $94(51-141)$ \\
Lampsilis siliquoidea & 228 & 7 & 18 & $54(14-110)$ \\
Lasmigona compressa & 162 & 8 & 16 & $64(24-92)$ \\
Lasmigona costata & 952 & 2 & 29 & $100(17-191)$ \\
Ligumia nasuta & 1 & 13 & 1 & 79 \\
Ligumia recta & 29 & 10.7 & 10 & $123(65-157)$ \\
Pyganodon grandis & 344 & 5 & 11 & $83(36-132)$ \\
Strophitus undulatus & 331 & 5.3 & 22 & $61(26-106)$ \\
Villosa iris & 401 & 4.3 & 21 & $70(17-115)$ \\
\hline
\end{tabular}

${ }^{(1)}$ mean value over three sampling events; ${ }^{(2)}$ percentage of sites species collected from.
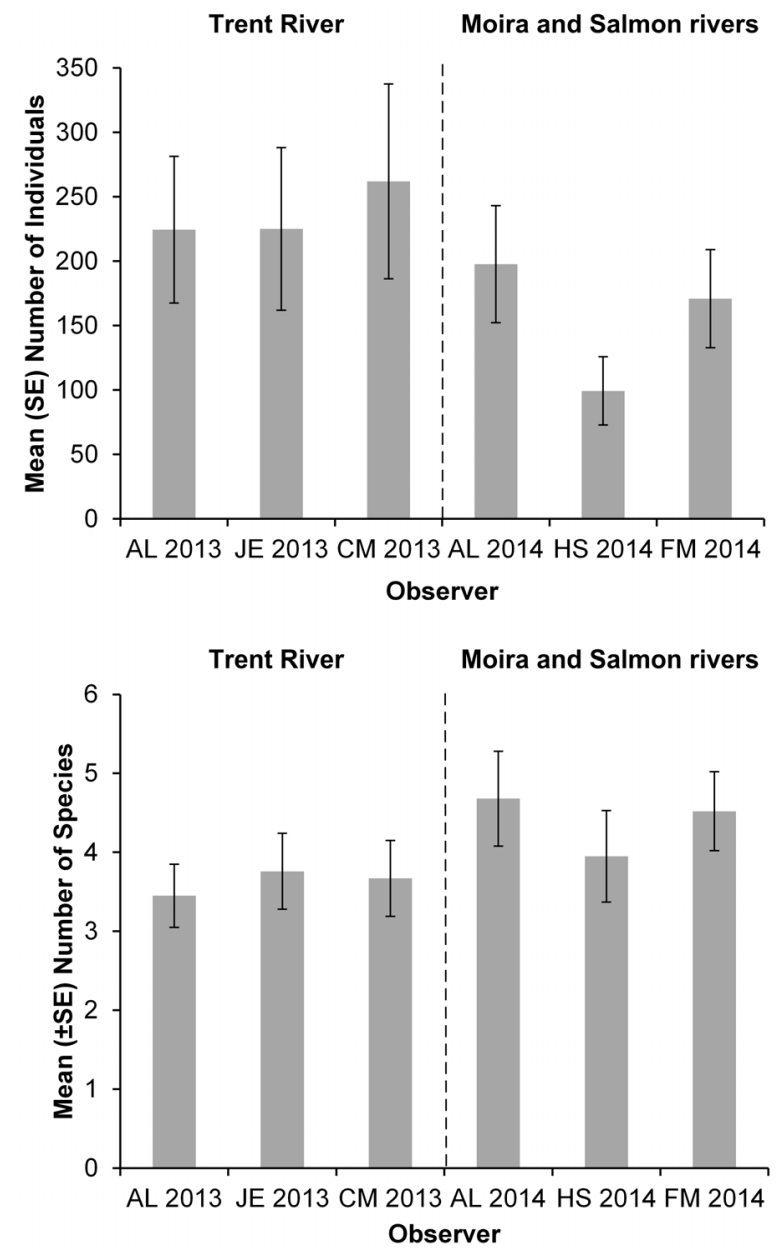

Fig. 1. Among field crew member (searcher) variation in number of individuals and mussel species collected during timed-search $(4.5 \mathrm{~h})$ surveys of 54 southern Ontario river sites.

from the Trent River (Figure 1). There was at least moderate agreement among field crew members (Kappa $>0.45$, Landis and Koch, 1977) regarding the presence of each species at sampling sites. For eight of the 11 species detected, agree- ment ranged from substantial to almost perfect (Kappa: 0.61 to 0.96 ). There were more noticeable differences among crew members in 2014; with one member collecting 45 to $50 \%$ fewer individuals and detecting 13 to $16 \%$ fewer species from the Moira and Salmon rivers. Regarding the presence of eight of the 11 species $(73 \%)$ detected, there was moderate to substantial agreement among field crew members (Kappa: 0.48 to 0.79). For Eastern Elliptio, Flutedshell and Giant Floater (Pyganodon grandis), agreement was only fair (Kappa: 0.21 to 0.30 ).

\subsection{Impact of sampling effort on species detection}

In comparison to $1.5 \mathrm{~h}$ of search effort, species detection occurred at a greater rate when search effort was 3.0 or $4.5 \mathrm{~h}$ (Figure 2). Rarefaction curves also indicate that a small number of species will only be detected by searching longer than $1.5 \mathrm{~h}$. Fifty-seven percent of mussel species collected from each site were classified as locally rare, $10 \%$ uncommon and $33 \%$ common. For uncommon and common species, detection typically occurred during the first $1.5 \mathrm{~h}$ of searching (72 and $94 \%$ of detections, respectively) (Figure 3). However, only $31 \%$ of detections of locally rare species were in the first $1.5 \mathrm{~h}$. For rare species, detection improved with greater search effort ( $48 \%$ of detections in the second $1.5 \mathrm{~h}$ period, and $21 \%$ of detections in the third $1.5 \mathrm{~h}$ period).

In all cases, species detection was imperfect. While $76 \%$ of species detections occurred during the first sampling event, $20 \%$ of detections required a second sampling event and $4 \%$ required a third sampling event. Based on $4.5 \mathrm{~h}$ of search effort, detection probabilities ( $p$ ) for all species except Triangle Floater (Alasmidonta undulata) were high (>0.69) (Table 2). Only two repeat surveys are required to confidently determine whether most $(83 \%)$ mussel species are present at a site (based on $N_{\text {min }}$ ). It is predicted that four surveys are required to reliably detect Triangle Floater. While the percentage of sites occupied was higher for more abundant species, $4.5 \mathrm{~h}$ based detection probabilities were generally independent of species abundance.

Increasing search effort from 1.5 to $4.5 \mathrm{~h}$ resulted in a mean increase (calculated across species) of $25 \%$ to $p$ and $16 \%$ 


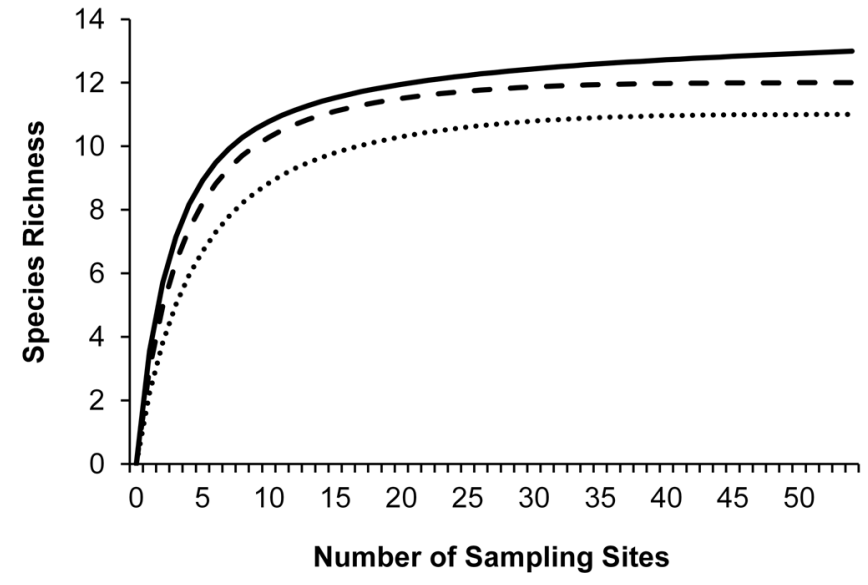

Fig. 2. Sample-based rarefaction curves associated with freshwater mussel collection data from $1.5 \mathrm{~h}(. .),. 3.0 \mathrm{~h} \mathrm{(--)}$ and 4.5 (-) $\mathrm{h}$ of search effort at river sampling sites. Species richness estimates were computed based on Mao's $\tau$ (Colwell et al., 2004).

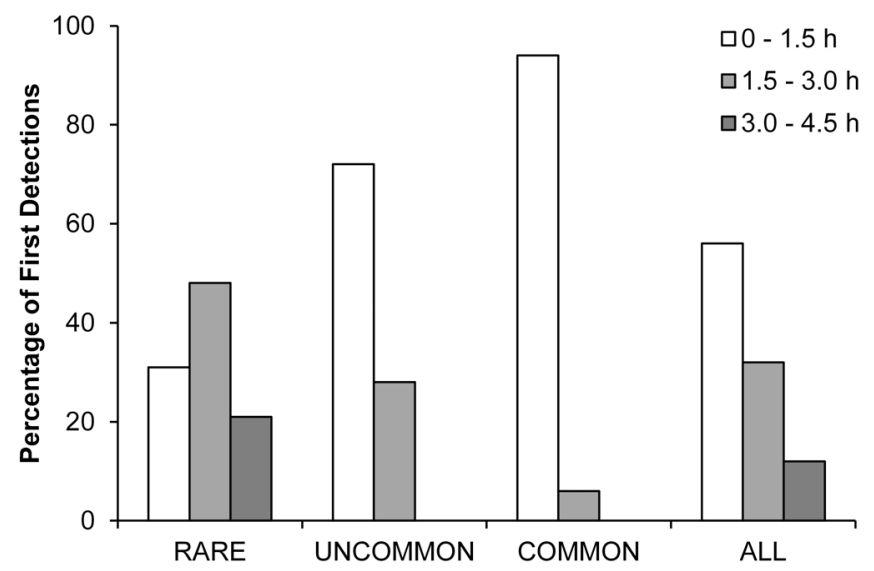

Fig. 3. Comparison of the percentage of first detections of rare, uncommon and common mussels associated with each sampling time interval. Species classification: rare $=1$ to 5 individuals per $4.5 \mathrm{~h}$; uncommon $=6$ to 10 individuals; common $>10$ individuals.

to $\psi$ (Table 2). The difference between detection probabilities calculated for $1.5 \mathrm{~h}$ and $4.5 \mathrm{~h}$ of search effort was largest for Elktoe (+0.39), Plain Pocketbook (Lampsilis cardium) (+0.23) and Triangle Floater $(+0.48)$. Based on non-overlapping CIs, significant improvements to mean $p$ ( $1.5 \mathrm{~h}$ search effort) were limited to Elktoe and Triangle Floater. Eastern Elliptio, Flutedshell and Triangular Floater occupancy estimates were strongly affected by search effort. Overall, the collection of fresh shells had little influence on detection probabilities (increased mean $p$ for all species from 0.82 to 0.83 ). Alternately, there was a large effect on occupancy estimates; mean $\psi$ for all species increased from 0.47 to 0.64 . Changes to occupancy estimates were greatest $(>0.20)$ for Creeper (Strophitus undulatus), Elktoe, Fatmucket and Triangle Floater. For all levels of search effort, $p$ and $\psi$ were positively correlated to the total number of individuals collected over the three sampling events $\left.p: r_{\mathrm{s}}=0.58-0.77, p<0.05 ; \psi: r_{\mathrm{s}}=0.65-0.78, p \leqslant 0.03\right)$.

\subsection{Impact of sampling effort on long-term monitoring}

For all species, power to detect future changes in mussel species distribution improved with greater search effort (Figure 4). In comparison to $1.5 \mathrm{~h}$, the power of $4.5 \mathrm{~h}$ timedsearch surveys was 20 to $54 \%$ greater. The detection of $70 \%$ declines in future site occupancy is likely for most species (including Rainbow). However, detecting declines in occupancy of $50 \%$ is only predicted for four species (Creek Heelsplitter, Cylindrical Papershell (Anodontoides ferussacianus), Eastern Elliptio, and Flutedshell). The inclusion of shells increased the species list to include Creeper, Elktoe, Fatmucket and Rainbow (power $=79$ for Rainbow). In almost all cases, power to detect small changes $(30 \%)$ is not predicted to be high. Power to detect $30 \%$ and $50 \%$ occupancy declines was strongly affected by search effort and fresh shell collection (Figure 4).

\section{Discussion}

Given the long-term nature of monitoring objectives, it is important that biologists and resource managers are confident that investments in sampling will provide data useful to detect species and track trends in distribution. The currently applied timed-search method used to survey Ontario rivers is based on $4.5 \mathrm{~h}$ of search effort (Metcalfe et al., 2000). The search effort recommendation was based on comparing frequencies of rare species detection and species richness estimates associated with $1.5,3.0$ and $4.5 \mathrm{~h}$ of cumulative search effort at 28 Ontario river sites. At the time of the study, $4.5 \mathrm{~h}$ was at least twice the effort typical of timed-search mussel surveys. More recent research has found that timed-searches of $<8 \mathrm{~h}$ severely underestimated mussel species richness at Illinois stream sites (Huang et al., 2011). At the sites sampled along the Moira, Salmon and Trent rivers, only $75 \%$ of species detections occurred during the first visit; evidence of substantial underestimation of species richness. While greater search effort (or number of sampling visits) may further improve detection, some species may only be collected by excavating river bed material. During recent quadrat-based sampling of Ontario river sites, between 11 and $36 \%$ of species detections required excavation (Reid and Morris, unpublished data). As an alternative to surveying a site for a constant length of time, other researchers have proposed spatially-based survey designs where search area is based on search efficiency (Smith, 2006) or hydromorphologically significant features (Lamand and Beisel, 2014).

Imperfect detection of freshwater mussels has been found to bias estimates of site occupancy (Wisniewski et al., 2013a), and population parameters such as density and survival (Smith, et al., 2010, Wisniewski et al., 2013b). In this study, detection of mussels using the timed-search method was imperfect. Species may have been missed by field staff on a given sampling date, or were unavailable for collection due to the burrowing behaviour of mussels (Haag, 2012). For most species, detection probabilities are still considered high; well above the minimum value $(p>0.3)$ recommended by Mackenzie et al., (2006) for occupancy-based studies. Based on these probabilities, two $4.5 \mathrm{~h}$ repeat surveys (with fresh shell collection) are recommended in order to confidently assess 
Table 2. Comparison of detection probability $(p)$ and occupancy $(\psi)$ estimates for 12 freshwater mussel species across four different levels of sampling effort. Estimates were calculated using a constant probability, single-season occupancy model (PRESENCE 9.7 software). For detection probability, $95 \%$ confidence intervals are provided in parentheses.

\begin{tabular}{|c|c|c|c|c|c|c|c|c|}
\hline \multirow{2}{*}{ Species } & \multicolumn{2}{|l|}{$1.5 \mathrm{~h}$} & \multicolumn{2}{|l|}{$3 \mathrm{~h}$} & \multirow{2}{*}{$4.5 \mathrm{~h}$} & \multirow[b]{2}{*}{$\psi$} & \multicolumn{2}{|c|}{$4.5 \mathrm{~h}$ plus shells } \\
\hline & $\bar{p}$ & $\psi$ & $\bar{p}$ & $\psi$ & & & $\bar{p}$ & $\psi$ \\
\hline Alasmidonta marginata & $0.38(0.12,0.75)$ & 0.28 & $0.77(0.51,0.91)$ & 0.32 & $0.77(0.51,0.91)$ & 0.32 & $0.89(0.76,0.95)$ & 0.79 \\
\hline Alasmidonta undulata & $0.09(0.05,0.14)$ & $*$ & $0.63(0.34,0.85)$ & 0.10 & $0.57(0.32,0.79)$ & 0.14 & $0.74(0.60,0.84)$ & 0.38 \\
\hline Anodontoides ferussacianus & $0.78(0.63,0.87)$ & 0.40 & $0.80(0.68,0.89)$ & 0.49 & $0.84(0.73,0.91)$ & 0.54 & $0.80(0.70,0.88)$ & 0.67 \\
\hline Elliptio complanata & $0.90(0.83,0.95)$ & 0.69 & $0.87(0.80,0.92)$ & 0.80 & $0.85(0.78,0.90)$ & 0.88 & $0.92(0.87,0.96)$ & 0.89 \\
\hline Lampsilis cardium & $0.59(0.38,0.77)$ & 0.20 & $0.86(0.70,0.94)$ & 0.22 & $0.82(0.68,0.90)$ & 0.32 & $0.80(0.68,0.88)$ & 0.45 \\
\hline Lampsilis siliquoidea & $0.70(0.56,0.81)$ & 0.36 & $0.77(0.64,0.86)$ & 0.39 & $0.82(0.72,0.89)$ & 0.49 & $0.77(0.68,0.84)$ & 0.84 \\
\hline Lasmigona compressa & $0.69(0.53,0.81)$ & 0.46 & $0.81(0.68,0.90)$ & 0.50 & $0.83(0.72,0.91)$ & 0.57 & $0.82(0.71,0.89)$ & 0.75 \\
\hline Lasmigona costata & $0.65(0.53,0.76)$ & 0.51 & $0.69(0.59,0.78)$ & 0.66 & $0.79(0.70,0.86)$ & 0.69 & $0.82(0.74,0.88)$ & 0.76 \\
\hline Ligumia recta & $0.64(0.40,0.82)$ & 0.15 & $0.67(0.49,0.81)$ & 0.25 & $0.69(0.53,0.82)$ & 0.27 & $0.76(0.62,0.85)$ & 0.38 \\
\hline Pyganodon grandis & $0.69(0.46,0.85)$ & 0.15 & $0.67(0.49,0.81)$ & 0.25 & $0.80(0.65,0.90)$ & 0.26 & $0.81(0.66,0.90)$ & 0.30 \\
\hline Strophitus undulatus & $0.82(0.69,0.90)$ & 0.35 & $0.84(0.74,0.91)$ & 0.44 & $0.92(0.82,0.96)$ & 0.44 & $0.80(0.71,0.87)$ & 0.65 \\
\hline Villosa iris & $0.78(0.65,0.87)$ & 0.35 & $0.78(0.67,0.87)$ & 0.44 & $0.88(0.78,0.94)$ & 0.45 & $0.93(0.85,0.97)$ & 0.52 \\
\hline Mean & 0.69 & 0.35 & 0.78 & 0.43 & 0.82 & 0.47 & 0.83 & 0.64 \\
\hline
\end{tabular}

*: data insufficient to model occupancy.

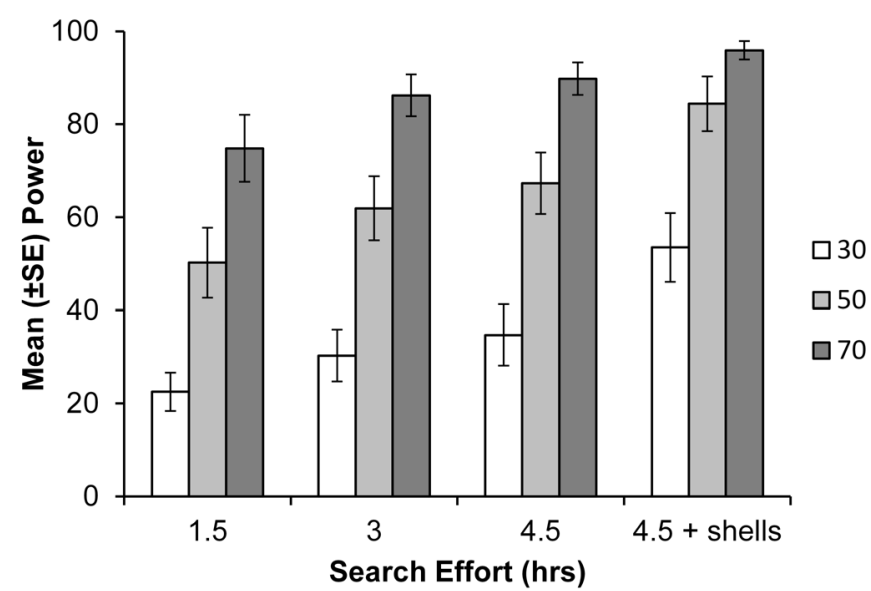

Fig. 4. Influence of search effort on the power of visual-tactile surveys to detect changes in riverine mussel distribution. Power was calculated for declines in site occupancy of 30\%, 50\% and $70 \%$.

species occurrence at an individual site (Pellet and Schmidt, 2005), and three repeat surveys are recommended for larger scale occupancy-based monitoring programs (MacKenzie and Royle, 2005). While detection probabilities estimated for 1.5 and $3.0 \mathrm{~h}$ of search effort were similar, results indicate that rare species detection and occupancy estimates are greatly improved at the recommended search effort.

For a third of the species encountered, fresh shell collection increased estimates of site occupancy by 48 to $171 \%$. Muskrats and raccoons can consume large quantities of mussels, and leave behind easily detected fresh shells and shell middens (i.e. piles). These animals selectively prey on certain sizes and species present at mussel beds. Muskrat have been found to preferentially select medium-sized, round and inflated shells; although large-thin shelled species are also taken (Watters, 1994; Haag, 2012). Therefore, shell data will be biased and have an unequal impact on species occupancy esti- mates. The largest increases to occupancy estimates were associated with species with smaller and inflated shells. In this study, it was assumed that: (1) fresh shells were of local origin (not washed into the site from an upstream location); and (2) any movement of shells did not change the occupancy status of a species between repeat sampling events. Considering the substantial influence of shells on occupancy estimates, it is important that these assumptions are tested by future field study. If not validated, fresh shells would only be useful for developing river-specific species lists.

Mussel surveys are affected by the abundance and biological characteristics of species in mussel beds, the physical habitat conditions of survey sites, and the capabilities of field staff (Strayer and Smith, 2003; Wisniewski et al., 2013a). Despite the use of a standardized sampling method, these factors can result in heterogeneous detection probabilities for populations found in different rivers. When sampling conditions are worse (e.g. poor water clarity) or populations are at lower densities than encountered during the development of sampling protocols, search effort may not be adequate to reliably detect species at risk (Dextrase et al., 2014). While such factors were not included as covariates in occupancy-models, some comments can be made regarding the influence of abundance, shell size, and field staff experience on timed-search surveys results.

Elktoe and Triangle Floater were two of the smallest species collected in this study and comprised only a small percentage of all mussels collected (Table 1). Detection probabilities for these two species were substantially less than other species when only $1.5 \mathrm{~h}$ was spent searching. The potential effect of low abundance and small shell size was less evident when more time was spent searching for mussels. Positive correlations between abundance and detection probabilities are consistent with theoretical expectations for sampling populations of rare mussels (Green and Young, 1993). Surface detection of mussels can be affected by searcher experience; with more experienced staff being less affected by sampling fatigue and better able to negotiate challenging sampling conditions (Wisniewski et al., 2013a). There was strong agreement 
in mussel collections among crew members in 2013, but agreement was only moderate in 2014. Interestingly, there was much less variation in sampling experience among 2014 staff (one year) than in 2013 (seven years).

Occupancy modelling has been applied to investigate factors influencing species detection and distribution, and the effect of drought on freshwater mussels in the lower Flint River basin, Georgia (USA) (Shea et al., 2013; Wisniewski et al., 2013a). However, in comparison to other aquatic taxa such as fishes and amphibians, the use of replicate survey data and occupancy models to estimate freshwater mussel detection probabilities is rare. To date, survey design has been informed by empirical relationships between search effort and species richness (Metcalfe et al., 2000; Huang et al., 2011) and theoretical relationships between species abundance and detection probability (Strayer and Smith, 2003). Given that mussel species detection is imperfect, occupancy models are well suited for designing timed-search species inventories and monitoring. In this study, detection probabilities were used to: (1) estimate the number of repeat surveys required to confidently detect species; and (2) jointly with occupancy estimates, evaluate the power of timed-search surveys to detect distribution declines of magnitudes relevant to species status assessments. Despite large differences in relative abundance, among-species differences in detectability were relatively limited at $4.5 \mathrm{~h}$; therefore, sampling recommendations will be broadly sufficient. Larger differences in the detectability of mussel species have been reported in more diverse rivers (Wisniewski et al., 2013a). The mussel fauna present in the Moira, Salmon and Trent rivers is less diverse (and has fewer imperiled species) than southwestern Ontario rivers. Although the current timedsearch protocol was originally developed in southwestern Ontario rivers, species detection probabilities should be estimated for these rivers in order to ensure sampling sufficiency across species of interest.

Incorporating detection estimates is recommended for future mussel monitoring programs as: (1) it provides a measure of sampling confidence that can be used to adjust detection/non-detection data (Wisniewski et al., 2013a); and (2) the influence of uncontrollable factors (e.g. weather or flow conditions) during surveys on species detection can be assessed through occupancy-based models (Tingley and Beissinger, 2009). Over time, such an approach would address concerns related to "true absences" or the comparability between surveys when historical data are used for species status assessment. The collection of replicate survey data can be done on separate dates within a season, or by recording and treating collections made by multiple observers as discrete sampling events (MacKenzie et al., 2006). The second option would not require additional resources to complete field sampling, and would reduce the risk of violating the closure assumption of occupancy models.

Acknowledgements. Research was supported by Fisheries and Oceans Canada and Ontario Ministry of Natural Resources and Forestry species-at-risk program funds. Mussel sampling was done by A. LeBaron, J. Epp, C. Malcolm, F. Montgomery and H Smith Data entry and compilation was assisted by V. Kopf. The manuscript was improved by comments from three anonymous reviewers.

\section{References}

Agresti A., 2013. Categorical data analysis, 3rd edition, John Wiley \& Sons, Hobekon, 714 p.

Amyot J.-P. and Downing J.A., 1991. Endo- and epibenthic distribution of the unionid mollusc Elliptio complanata. J. North. Am. Benthol. Soc., 10, 280-285.

Chapman L.J. and Putnam D.F., 1984. The Physiography of Southern Ontario, 3rd edition, Ontario Geological Survey Special, Toronto, Vol. 2, 270 p.

Clarke A.H., 1992. Ontario's Sydenham River, an important refugium for native freshwater mussels against competition from the zebra mussel, Dreissena polymorpha. Malacol. Data Net., 3, 43-55.

Cohen J., 1988. Statistical Power Analysis for the Behavioral Sciences, 2nd edition, Lawrence Erlbaum Associates, Hillsdale, $590 \mathrm{p}$.

Colwell R.K., Mao C.X. and Chang J., 2004. Interpolating, extrapolating, and comparing incidence-based species accumulation curves. Ecology, 85, 2717-2727.

Committee on the Status of Endangered Wildlife in Canada (COSEWIC), 2013. Wildlife Species Search. Committee on the Status of Endangered Wildlife in Canada. Available from: http://www.cosewic.gc.ca/eng/sct1/searchform_e.cfm (accessed September 17 2013).

Cudmore B., Mandrak N.E., Morris T.J. and Edwards A., 2006. Allowable harm analysis workshops for freshwater species at risk in central and Arctic region, Canadian Science Advisory Secretariat Proceedings Series 2006/026.

Dextrase A.J., Mandrak N.E., Barnucz J., Bouvier L., Gaspardy R. and Reid S.M. 2014. Sampling effort required to detect fishes at risk in Ontario, Canadian Manuscript Report of Fisheries and Aquatic Sciences 3024.

Epp J.M., Morris T.J. and McNichols-O'Rourke K.A., 2013. A preliminary search for Epioblasma torulosa rangiana (Northern Riffleshell) in the Maitland River, Canadian Manuscript Report of Fisheries and Aquatic Sciences 3025.

Fisheries and Oceans Canada (DFO), 2011. Assessment of methods for the identification of critical habitat for freshwater mussels. Canadian Science Advisory Secretariat Science Advisory Report 2011/047.

Fleiss J.L., Levin B. and Paik MC., 2003. Statistical methods for rates and proportions, 3rd edition, John Wiley \& Sons, Hoboken, $800 \mathrm{p}$.

Gibbs J.P., Droege S. and Eagle P., 1998. Monitoring populations of plants and animals. Bioscience, 48, 935-940.

Green R.H. and Young R.C., 1993. Sampling to detect rare species. Ecol. Appl., 3, 351-356.

Guillera-Arroita G. and Lahoz-Monfort J.J., 2012. Designing studies to detect differences in species occupancy: power analysis under imperfect detection. Methods Ecol. Evol., 3, 860-869.

Haag W.R., 2012. North American freshwater mussels. Natural history, ecology, and conservation, Cambridge University Press, Cambridge, $505 \mathrm{p}$.

Hammer Ø., Harper D.A.T. and Ryan P.D., 2001. PAST: paleontological statistics software package for education and data analysis. Palaeontol. Electronica, 4, 1-9.

Hornbach D.J. and Deneka T., 1996. A comparison of a qualitative and a quantitative collection method for examining freshwater mussel assemblages. J. North. Am. Benthol. Soc., 15, 587-596.

Huang J., Cao Y. and Cummings K.S., 2011. Assessing sampling adequacy of mussel diversity surveys in wadeable Illinois streams. J. North. Am. Benthol. Soc., 30, 923-934. 
Jeffress M.R., Paukert C.P., Sandercock B.K. and Gipson P.S., 2011. Factors affecting detectability of river otters during sign surveys. J. Wildlife Manage., 74, 144-150.

Lamand F.L. and Beisel J.-N., 2014. Proposal for a simple hydromorphological habitat survey method for freshwater bivale (Unionidae) inventories. Aquat. Ecol., 48, 237-245.

Landis J.R. and Koch G.G., 1977. The measurement of observer agreement for categorical data. Biometrics, 33, 159-174.

Lucy F., Burlakova L.E., Karatayev A., Mastitsky S. and Zanatta D.T., 2013. Zebra mussel impacts on unionids: A synthesis of trends in North America and Europe. In: Nalepa T.F. and Schloesser D.W. (eds.), Quagga and Zebra Mussels: Biology, Impact, and Control, 2nd edition, CRC Press, Boca Raton, 623-645.

MacKenzie D.I. and Royle J.A., 2005. Designing occupancy studies: general advice and allocating survey effort. J. Appl. Ecol., 42, $1105-1114$.

MacKenzie D.I., Nichols J.D., Lachman G.B., Droege S., Royle J.A. and Langtimn C.A., 2002. Estimating site occupancy when detection probabilities are less than one. Ecology, 83, 2248-2255.

MacKenzie D.I., Nichols J.D., Royle J.A., Pollock K.H., Hines J.E. and Bailey L.L., 2006. Occupancy estimation and modeling: inferring patterns and dynamics of species occurrence. Elsevier, San Diego, 324 p.

McNichols-O'Rourke K.A., Robinson A. and Morris T.J., 2012. Summary of freshwater mussel timed search surveys in southwestern Ontario in 2010 and 2011, Canadian Manuscript Report of Fisheries and Aquatic Sciences 3009.

Metcalfe-Smith J.L., Staton S.K., Mackie G.L. and Lane N.M., 1998. Changes in the biodiversity of freshwater mussels in the Canadian waters of the lower Great Lakes drainage basin over the past 140 years. J. Gt. Lakes Res., 24, 845-858.

Metcalfe-Smith J.L., DiMaio J., Staton S.K. and Mackie G.L., 2000. Effect of sampling effort on the efficiency of the timed search method for sampling freshwater mussel communities. J. N. Am. Benthol. Soc., 19, 725-732.

Metcalfe-Smith J.L., MacKenzie A., Carmichael I. and McGoldrick D., 2005. Photo Field Guide to the Freshwater Mussels of Ontario, St. Thomas Field Naturalist Club, 60 p.

Ontario Ministry of Natural Resources and Forestry (MNRF). 2014. Species at Risk in Ontario (SARO) List. Available from: http://www.ontario.ca/environment-and-energy/speciesrisk-ontario-list [accessed September 16 2014].

Pearl C.A., Adams M.J. and McCreary B., 2013. Habitat and co-occurrence of native and invasive crayfish in the Pacific Northwest, USA. Aquat. Invasions, 8, 171-184.

Pellet J. and Schmidt B., 2005. Monitoring distributions using call surveys: estimating site occupancy, detection probabilities and inferring absence. Biol. Conserv., 123, 27-35.
Randklev C.R., Johnson M.S., Tsakiris E.T., Groce J. and Wilkins N., 2013. Status of the freshwater mussel (Unionidae) communities of the mainstem of the Leon River, Texas. Aquat. Conserv. Mar. Freshw. Ecosyst., 23, 390-404.

Reid S.M., Lean J. and Carl L., 2005. Influence of riffle characteristics, surficial geology, and natural barriers on the distribution of the channel darter (Percina copelandi) in the Lake Ontario basin. Environ. Biol. Fishes, 72, 241-249.

Schloesser D.W. and Nalepa T.F., 1994. Dramatic decline of unionid bivalves in the offshore waters of western Lake Erie after infestation by the zebra mussel, Dreissena polymorpha. Can. J. Fish. Aquat. Sci., 51, 2234-2242.

Schloesser J.T., Paukert C.P., Doyle W.J., Hill T.D. and Steffensen K.D., 2012. Heterogeneous detection probabilities for imperiled Missouri River fishes: implication for large river monitoring programs. Endanger. Species Res., 16, 211-224.

Shea C.P., Peterson, J.T., Conroy, M.J. and Wisniewski, J.M., 2013. Evaluating the influence of land use, drought and reach isolation on the occurrence of freshwater mussel species in the lower Flint River Basin, Georgia (USA). Freshwater Biol., 58, 382-395.

Smith D.H.V., Jones B., Randall L. and Prescott D.R.C., 2014. Difference in detection and occupancy between two anurans: the importance of species-specific monitoring. Herpetol. Conserv. Biol., 9, 267-277.

Smith D.R., 2006. Survey design for detecting rare freshwater mussels. J. N. Am. Benthol. Soc., 25, 701-711.

Smith D.R., Gray B.R., Newton T.J., and Nichols D., 2010. Effect of imperfect detectability on adaptive and conventional sampling: simulated sampling of freshwater mussels in the upper Mississippi River. Environ. Monit. Assess., 170, 499-507.

Strayer D.L. and Smith D.R., 2003. A Guide to Sampling Freshwater Mussel Populations. American Fisheries Society, Bethesda, $103 \mathrm{p}$.

Tingley M.W. and Beissinger S.R., 2009. Detecting range shifts from historical species occurrences: new perspectives on old data. Trends Ecol. Evol., 24, 625-633.

Villella R.F., Smith D.R. and LeMarié D.P., 2004. Estimating survival and recruitment in a freshwater mussel population using markrecapture techniques. Am. Midl. Nat., 151, 114-133.

Watters G.T. 1994. Sampling freshwater mussel populations: the bias of muskrat middens. Walkerana, 7, 63-69.

Williams J.D., Warren M.L., Cummings K.S., Harris J.L. and Neves R.J., 1992. Conservation status of the freshwater mussels of the United States and Canada. Fisheries, 18, 6-22.

Wisniewski J.M., Rankin N.M, Weiler D.A, Strickland B.A. and Chandler H.C., 2013a. Occupancy and detection of benthic invertebrates: a case study of unionids in the lower Flint River, Georgia, USA. Freshwater Sci. 32, 1122-1135.

Wisniewski J.M., Shea C.P., Abbott S., and Stringfellow R.C., $2013 b$. Imperfect recapture: a potential source of bias in freshwater mussel studies. Am. Midl. Nat. 170, 229-247. 